\title{
Performance Improvement of Dye-Sensitized Solar Cell- (DSSC-) Based Natural Dyes by Clathrin Protein
}

\author{
Prihanto Trihutomo $\mathbb{D}^{1,2}$ Sudjito Soeparman, ${ }^{1}$ Denny Widhiyanuriyawan, ${ }^{1}$ and Lilis Yuliati ${ }^{1}$ \\ ${ }^{1}$ Department of Mechanical Engineering, Brawijaya University, Jl. Veteran, Malang 65145, Indonesia \\ ${ }^{2}$ Department of Mechanical Engineering, State University of Malang, Jl. Semarang 5, Malang 65145, Indonesia
}

Correspondence should be addressed to Prihanto Trihutomo; prihanto.trihutomo.ft@um.ac.id

Received 14 November 2018; Accepted 16 April 2019; Published 9 June 2019

Academic Editor: Giulia Grancini

Copyright (C) 2019 Prihanto Trihutomo et al. This is an open access article distributed under the Creative Commons Attribution License, which permits unrestricted use, distribution, and reproduction in any medium, provided the original work is properly cited.

\begin{abstract}
Dye-Sensitized Solar Cell (DSSC) is a solar cell device that works using electrochemical principles in which sensitive dyes are absorbed in the $\mathrm{TiO}_{2}$ photoelectrode layer. The problem of DSSC-based natural dyes is the lower efficiency than silicon solar cells. This low efficiency is due to the barrier of electron transfer in the $\mathrm{TiO}_{2}$ semiconductor layer. In this study, the addition of clathrin protein to the $\mathrm{TiO}_{2}$ layer was used to increase electron transfer in the semiconductor layer resulting in improved DSSC performance. Clathrin is a protein that plays a role in the formation of transport vesicle membrane in eukaryotic cells. The method used in this study is clathrin protein with a concentration of $0 \%, 25 \%, 50 \%$, and $75 \%$ added to $\mathrm{TiO}_{2}$ in $\mathrm{DSSC}_{\text {structure. }}$ Photovoltaic characteristics of DSSC were measured using a data logger to determine the performance of DSSC, layer morphology was analyzed using Scanning Electron Microscopy (SEM), the element content in DSSC was analyzed using Energy-Dispersive X-ray Spectroscopy (EDS), and functional groups in DSSC layers were analyzed using Fourier-Transform Infrared Spectroscopy (FTIR). The result of this study is the addition of clathrin protein can improve DSSC performance, which resulted in the highest performance of DSSC on $75 \%$ clathrin protein addition with efficiency $=1.465 \%, I_{\mathrm{sc}}=5.247 \mathrm{~mA}$, and $V_{\mathrm{oc}}$ $=657 \mathrm{mV}$. From the results of SEM analysis, it appears that clathrin protein molecules fill the cavities in $\mathrm{TiO}_{2}$ molecules. EDS analysis shows an increase in carbon, oxygen, and phosphorus content in $\mathrm{TiO}_{2}$ layers with increasing clathrin protein concentration. FTIR analysis shows an increasingly sharp absorption in the FTIR spectrum of protein-forming functional groups by increasing clathrin protein concentration in DSSC.
\end{abstract}

\section{Introduction}

An interesting development of solar cell technology today is that of solar cells developed by O'Regan and Grätzel in 1991 [1]. They introduced a new type of photochemical solar cell which is a type of solar cell exciton, that is, DyeSensitized Solar Cell (DSSC). Dye-Sensitized Solar Cell is very cheap to be prepared and environmentally friendly, and the structure of thin films is light compatible with automatic manufacturing [2].

This solar cell consists of a layer of nanoparticles deposited in a dye that functions to capture photon light (using a type of synthetic dye such as ruthenium complex or organic dye), conductor glass, electrode, and electrolyte counters, which are often also called Dye-Sensitized Solar Cells (DSSCs) [2].

Dye-Sensitized Solar Cell (DSSC) is a solar cell device that works using the electrochemical principle in which dye that is sensitive to visible light is absorbed in the $\mathrm{TiO}_{2}$ photoelectrode layer. This dye will capture the energy of the photons which comes from light, then captured energy will be converted into electrical energy through a series of electron transfers in its layer [1].

The problem of Dye-Sensitized Solar Cell is the efficiency that is still low compared to silicon solar cells [3]. The efficiency of DSSC uses natural dyes about $0.89 \%$ [4], while the efficiency of silicon solar cells is approximately 20\% [5]. Low efficiency is due to a high level of recombination of free 
Clathrin triskelion

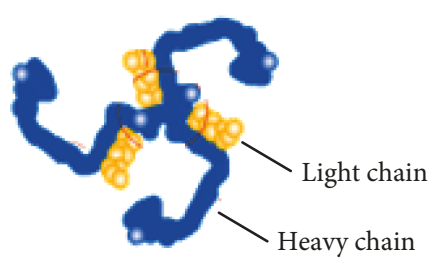

(a) Clathrin
Clathrin-coated vessicle

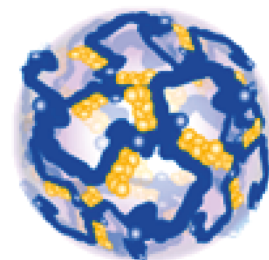

(b) Clathrin combination

FIGURE 1: Clathrin protein [13].

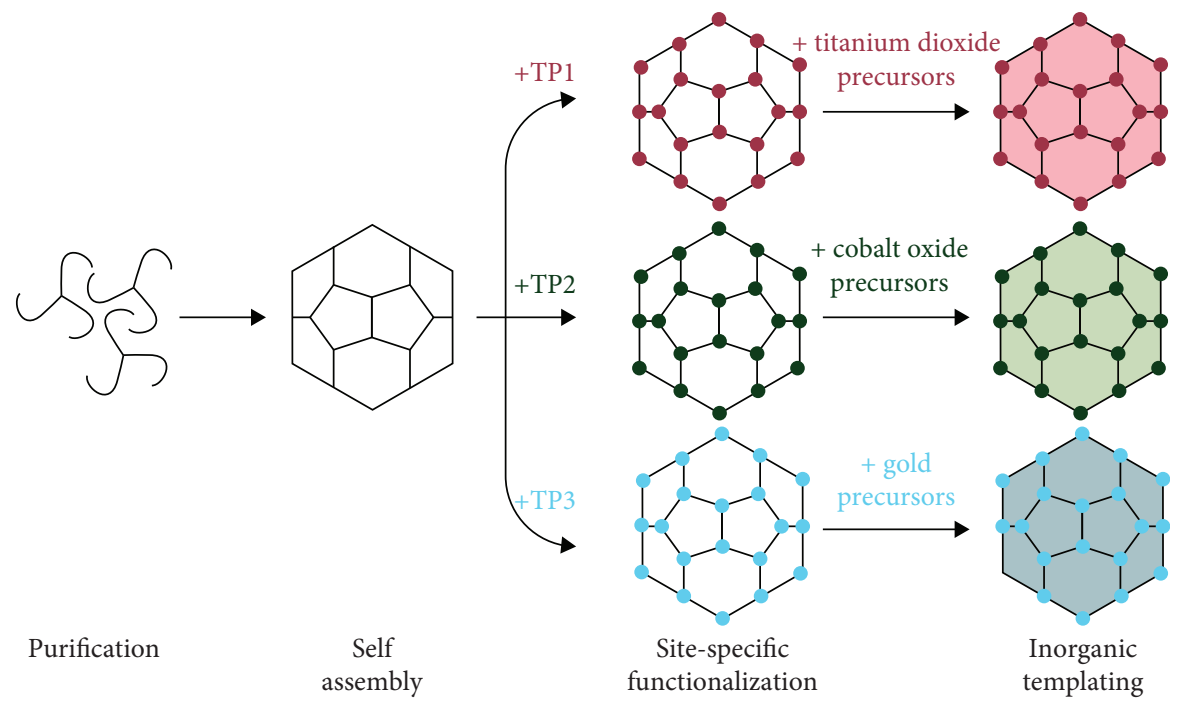

FIGURE 2: Application of clathrin on various materials [15].

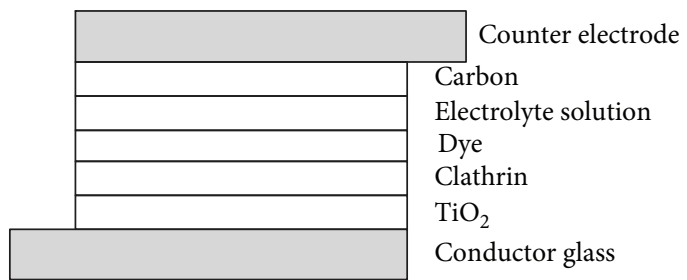

Figure 3: Structure of Dye-Sensitized Solar Cell.

electrons with oxidized dye molecules [6]. One that causes high levels of recombination is the limitation of electron transfer in $\mathrm{TiO}_{2}$ layers. The low transfer of electrons is due to less optimal contact between particles. Low electron transfer will cause electrons to be trapped at the boundary between $\mathrm{TiO}_{2}$ particles. Furthermore, electrons trapped at this grain boundary result in higher recombination opportunities [7].

Improved performance on DSSC can be done by deposition or addition of nanosized particles in the structure of the semiconductor layer. Previous research has been done to improve the performance of Dye-Sensitized Solar Cell such as $\mathrm{Hu}$ (2017) did by depositing Ag nanoparticles [8], Chava (2017) doping indium nanoparticles [9], Chou et al. adding bamboo charcoal powder particles in $\mathrm{TiO}_{2}$ [10], Kuang et al. adding $\mathrm{Li}^{+}$[11], and Arifin et al. adding $\mathrm{Zn}^{+}$particles [4].
Therefore, this study is aimed at investigating the effect of clathrin addition to the performance of Dye-Sensitized Solar Cell-based natural dyes. In this study, efforts to improve performance by adding clathrin protein to DyeSensitized Solar Cell that will fill the cavity or gap between $\mathrm{TiO}_{2}$ particles so that the contact between $\mathrm{TiO}_{2}$ particles becomes optimal and reduce the electron trapping in the grain boundaries of $\mathrm{TiO}_{2}$ particles so that the electron recombination level decreases because barrier in electron transfer process between $\mathrm{TiO}_{2}$ particles can be reduced result in improved DSSC performance.

Clathrin is found in every cell in the human body, animals, and plants as an important gate-keeper. Clathrin is a protein that plays an important role in the formation of the vesicle layer. Clathrin protein is used to build small vesicles to transport molecules in cells. Vesicles allow cells to communicate, transfer nutrients, import signaling receptors, mediate immune responses after taking extracellular samples, and clean up cell debris left behind by tissue inflammation. Clathrin is a three-legged protein with unique and relevant self-assembling properties in transport vesicle membrane formation in eukaryotic cells. This protein is shaped like a tripod: three leg spindles are joined together on one hub/shaft. Clathrin is composed of three clathrin heavy chain having a molecular weight of $180 \mathrm{kD}$ and three clathrin light chain having a molecular 


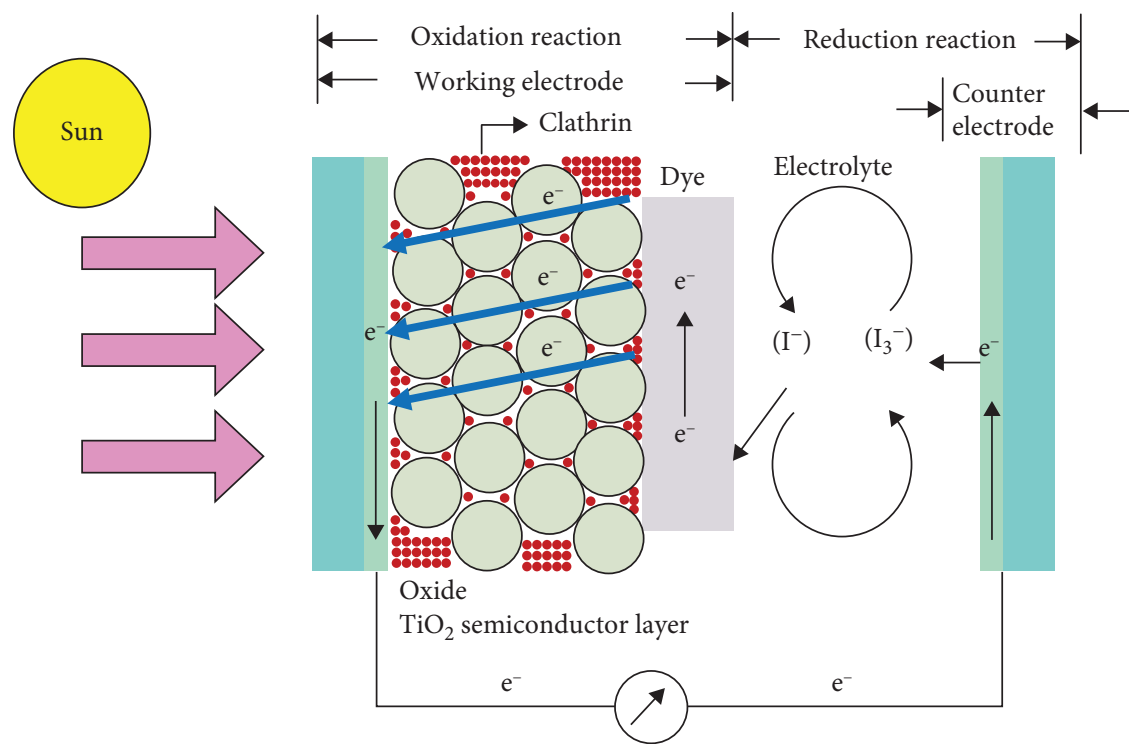

FIgURE 4: Mechanism of DSSC with the addition of clathrin.

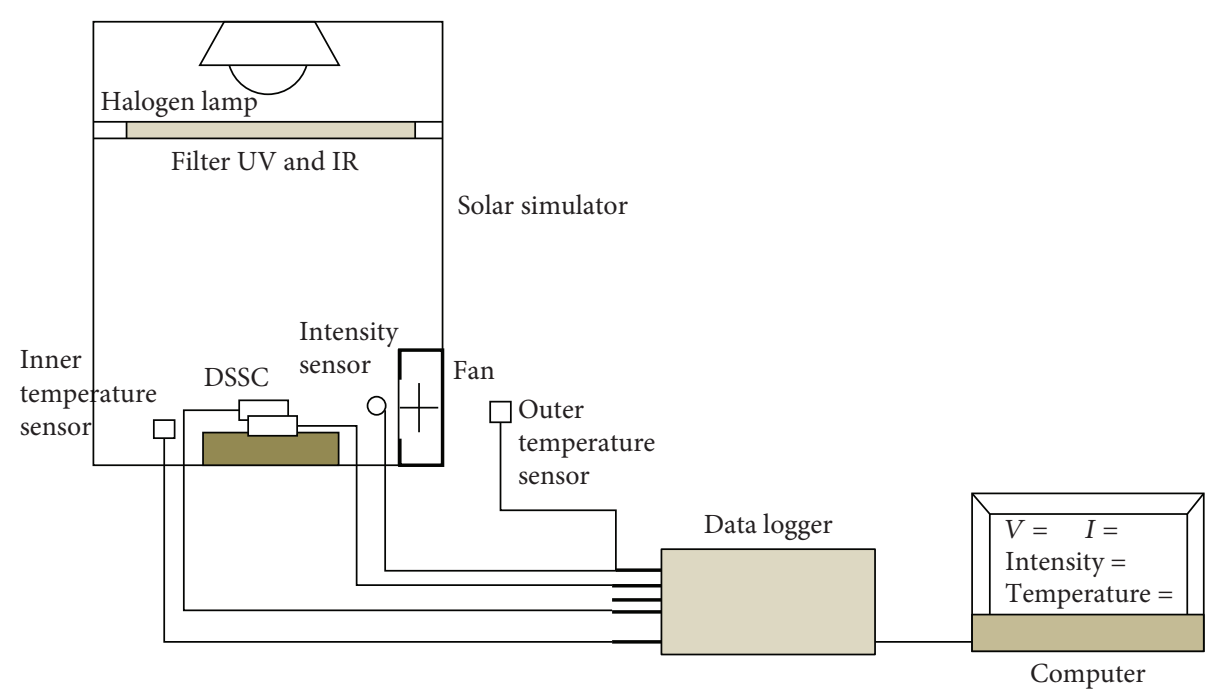

FIgURE 5: Research installation scheme.

weight of $30 \mathrm{kD}-40 \mathrm{kD}$. Clathrin molecules easily combine with each other to form a honeycomb-like lattice on the cell surface. The combination of the clathrin lattice is formed in sizes ranging from $30 \mathrm{~nm}$ to $100 \mathrm{~nm}$ from about 36 clathrin molecular units consisting of 108 heavy chain clathrin and 108 light chain clathrin. When the right molecule attaches to clathrin, the lattice structure of clathrin will wrap it in a pouch-like shape. This clathrin bag or pouch will take the molecule to its intended place [12]. The clathrin protein scheme is shown in Figure 1.

Clathrin plays an important role in the cell transportation system; this function caused clathrin to bind ions. The ability of clathrin to bind ions will give clathrin the ability to conduct electrons. Examples of ions that can bind clathrin are positive ions in iron [14].

Clathrin has a unique special ability to assemble itself. Clathrin will assemble itself into a skeletal structure that is useful in atoms and molecules. It can also infiltrate into multipurpose structures that stimulate the formation of complex molecules. Clathrin has been applied to various biotech materials as substrates. The materials that have been successfully added to clathrin are graphene, polymer, glass, and metal [15].

Figure 2 shows the application of clathrin on various materials. From the study of Schoen [16], it is known that clathrin can be bound to titanium dioxide, cobalt oxide, and gold. Titanium dioxide is a semiconductor material in DSSC [16].

\section{Materials and Methods}

The method used in this study is the experimental method to experimentally test the effect of adding clathrin protein to the performance of Dye-Sensitized Solar Cell. 


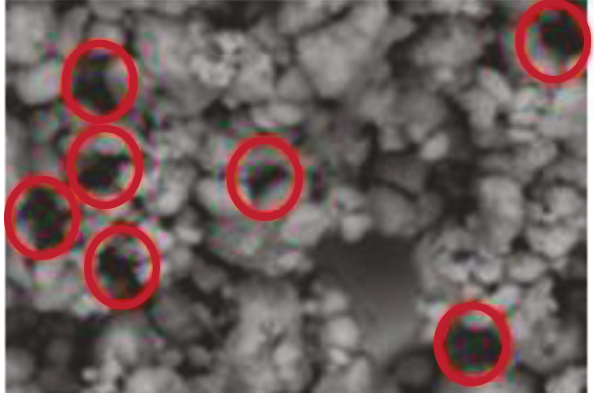

(a)

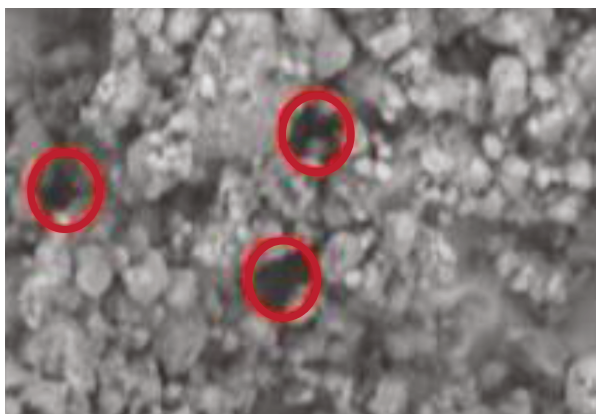

(c)

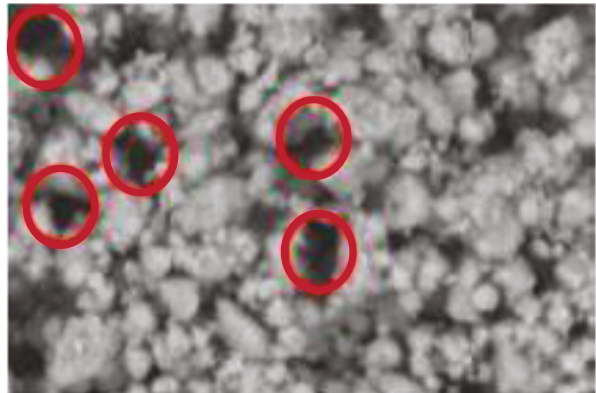

(b)

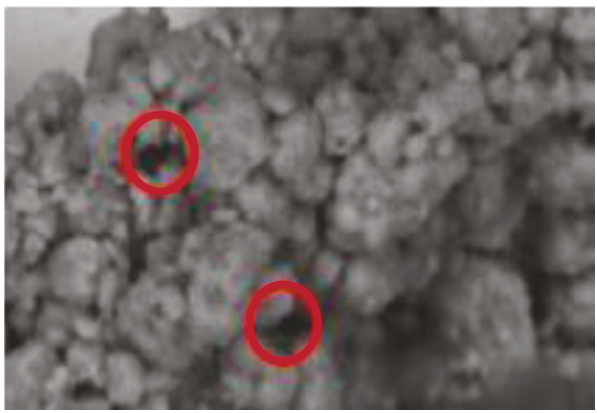

(d)

FIGURE 6: Morphology of 2500x magnification DSSC in various clathrin percentages: (a) 0\%; (b) 25\%; (c) 50\%; (d) $75 \%$.

First, the preparation of materials and equipment is carried out, namely, the provision of clathrin protein from cow brains, $\mathrm{TiO}_{2}$ paste, chlorophyll dye solution from papaya leaves, iodide/triiodide electrolyte solutions, FTO conductor glass, and carbon counter electrodes.

After that, the Dye-Sensitized Solar Cell assembly is carried out.

The technique used in this study is to add a clathrin protein in the structure of DSSC. The amount of clathrin protein which is added in DSSC based on the percentage of clathrin to the $\mathrm{TiO}_{2}$ is, namely, $0 \%, 25 \%, 50 \%$, and $75 \%$.

Dye-Sensitized Solar Cells were assembled as follows: $\mathrm{TiO}_{2}$ paste was applied to the conductor glass surface using a doctor blade technique with a $1 \times 1 \mathrm{~cm}^{2}$ polishing area which functions as the active area of the solar cell. The active area of DSSC is an effective area on FTO conductor glass that absorbs light and is the place area for the DSSC structure layer and also connects directly the working electrode conductor glass and electrode counter [17]. Then, the conductor glass which has been coated with $\mathrm{TiO}_{2}$ is burned in the furnace by setting the temperature at $450^{\circ} \mathrm{C}$ for 1 hour to enhance the bonding between the $\mathrm{TiO}_{2}$ paste and the conductor glass and also grow pores on $\mathrm{TiO}_{2}$, after which it is soaked in chlorophyll dye solution for 24 hours.

Then, clathrin protein and electrolyte solution are dripped on the layer. Furthermore, carbon counter electrodes are placed on top of $\mathrm{TiO} 2$, dye, clathrin, and electrolyte solutions according to the sandwich structures where each end is offset by $0.5 \mathrm{~cm}$ for electrical contact. After all these steps, solar cells are ready to be tested. Tests are carried out on solar cells in the form of measurements of current and voltage using a data logger to determine the performance of solar cells, SEM testing to determine the surface layer morphology, EDS testing to determine the elemental content of solar cells, and FTIR testing to determine the functional groups formed in the DSSC layer.

Figure 3 shows the structure of a fabricated DyeSensitized Solar Cell. Dye-Sensitized Solar Cell structure consists of several parts, namely, Fluorine Tin Oxide conductor glass as working electrode substrate, $\mathrm{TiO}_{2}$ semiconductor material, clathrin protein from cow brain, natural chlorophyll dye from papaya leaves, iodide/triiodide electrolyte solution, carbon material as catalyst, and Fluorine Tin Oxide glass as counter electrode.

The mechanism of DSSC with the addition of clathrin can be seen in Figure 4. Light provides energy to the electrons contained in the dye so that the electrons are excited to the conduction band of the $\mathrm{TiO}_{2}$ semiconductor. Clathrin protein added to DSSC fills the gap or cavity between $\mathrm{TiO}_{2}$ molecules can be acidic and basic at the same time. Acidic clathrin protein will capture electrons from oxidized dye molecules, and when it is basic, it will release electrons to $\mathrm{TiO}_{2}$. In this case, clathrin has a function as an electron bridge between dye and $\mathrm{TiO}_{2}$ as well as between $\mathrm{TiO}_{2}$ nanoporous particles thereby reducing the recombination of free electron with oxidized dye molecules. After the electron passes the $\mathrm{TiO}_{2}$ layer, it passes through the working electrode. Subsequently, the electron flows to the load before entrance to the counter electrode. Furthermore, these electrons are captured in a reduction reaction by electrolyte solutions. Finally, the oxidation reaction in electrolyte produces electrons to fill the hole left by the electron in the dye. This mechanism continues as a cycle to generate electricity in DSSC. 


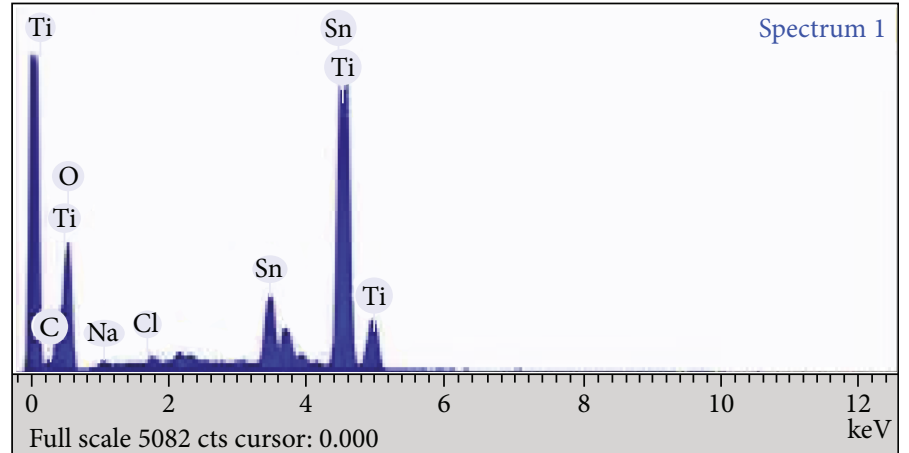

(a)

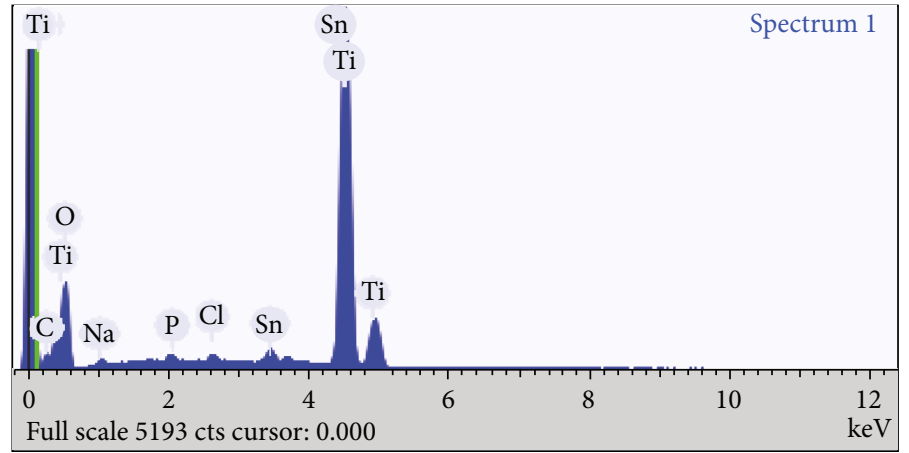

(b)

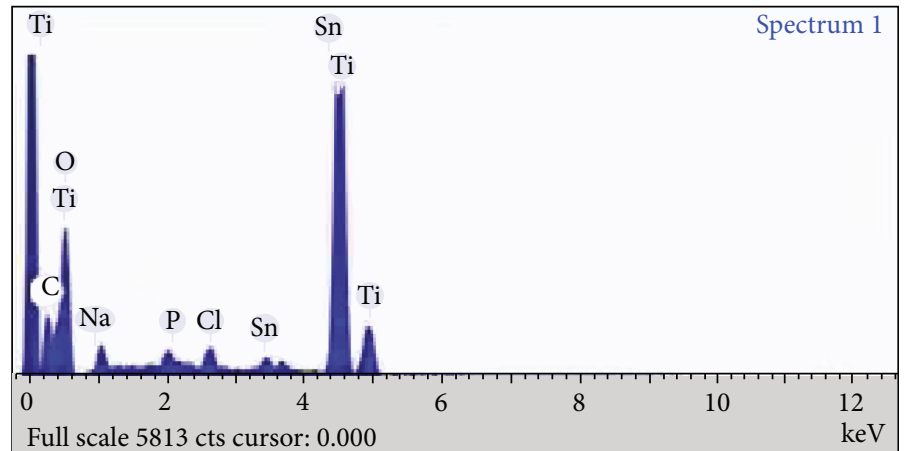

(c)

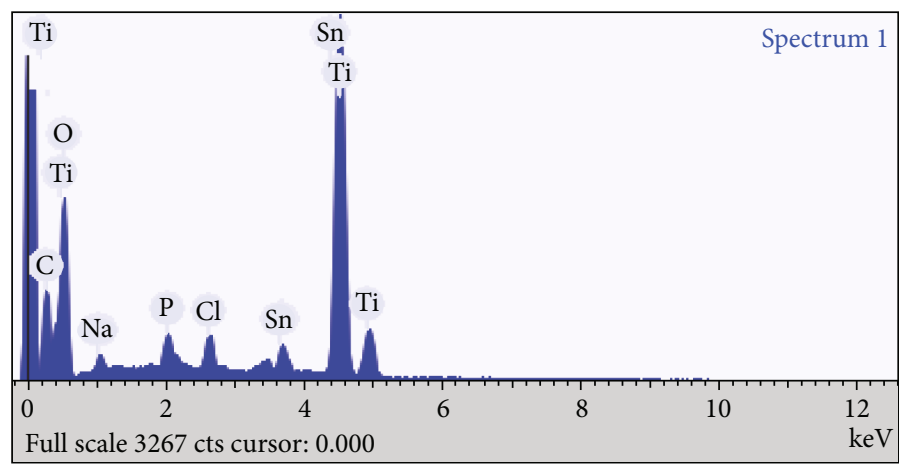

(d)

FIGURE 7: EDS spectra of DSSC in various clathrin percentages: (a) 0\%; (b) 25\%; (c) 50\%; (d) 75\%.

Electric current and voltage on DSSC are generated by irradiation using halogen lamps in solar simulators, then changes in the current and voltage generated are measured using a data logger to determine the performance of DSSC. Schematically, the research installation is shown in Figure 5.

The research equipment installation in Figure 5 consists of a solar simulator which is a place to provide lighting to 
the DSSC so as to produce the current and voltage to be measured to determine the performance of the DSSC. The solar simulator is $300 \mathrm{~mm}$ in length, $300 \mathrm{~mm}$ in width, and $500 \mathrm{~mm}$ in height. The solar simulator equipment has a $1000 \mathrm{~W} / \mathrm{m}^{2}$ intensity halogen lamp to provide lighting, UV and IR filters to produce visible light, and temperature sensors, intensity sensors, and fan that function to maintain a constant temperature. Current and voltage data generated in the DSSC are measured using the Arduino Uno ATmega328 data logger microcontroller.

The stages of data retrieval are as follows: the equipment is set according to Figure 5.

Then, the DSSC is placed in the middle with the distance to the illumination lamp set so that the intensity is $1000 \mathrm{~W} / \mathrm{m}^{2}$. Then, the lamp is turned on so that the current and voltage arise from the DSSC. The DSSC varied the percentage of clathrin protein content to $\mathrm{TiO}_{2}$, namely, $0 \%$, $25 \%, 50 \%$, and $75 \%$. Current and voltage data obtained are then transferred to the computer to calculate the efficiency.

The results of the calculation of current, voltage, and efficiency of each DSSC are then made graphs and tables for analysis.

\section{Results and Discussion}

3.1. Surface Morphology of DSSC. SEM (Scanning Electron Microscopy) analysis is aimed at determining the characteristics of the surface morphology of the DSSC layer. Figures $6(\mathrm{a})-6(\mathrm{~d})$ are a morphology of DSSC with variations in the percentage of clathrin to $\mathrm{TiO}_{2}$ that is $0 \%, 25 \%, 50 \%$, and $75 \%$ of the results of SEM analysis with a magnification of $2500 x$.

Figure 6(a) displays SEM images of $\mathrm{TiO}_{2}$ nanomaterials that have been coated on FTO glass. It is seen that the surface of the $\mathrm{TiO}_{2}$ thin layer is hollow or porous. The cavity in the thin layer serves to adsorb dye molecules on $\mathrm{TiO}_{2}$ [18]. But with the presence of these cavities, the electron transfer between $\mathrm{TiO}_{2}$ molecules becomes inhibited; this causes DSSC performance to be low.

From the results of SEM photos, Figures 6(b)-6(d) appear to increase the concentration of additional molecules from protein deposition to $\mathrm{TiO}_{2}$, the cavity or pore between $\mathrm{TiO}_{2}$ molecules decreases. In Figure 6(a), there are still many cavities between $\mathrm{TiO}_{2}$ molecules. In Figures 6(b)-6(d), with the increasing concentration of protein molecules that are deposited, the cavity appears to be decreasing, indicating that protein molecules fill the cavities between $\mathrm{TiO}_{2}$ molecules. This can be proven from the EDS results which show an increase in the number of molecules deposited in $\mathrm{TiO}_{2}$ molecules.

The presence of molecules deposited from this protein functions as a bridge for the electron transport to the anode to become faster because proteins are electrolytes [19]. The existence of this electron bridge can reduce recombination thereby increasing the performance of DSSC.

3.2. Content of DSSC Elements. Characterization of DSSC layers using EDS (Energy-Dispersive X-ray Spectroscopy) is used to determine the composition of elements in a sample
TABLE 1: Element content of DSSC in various clathrin percentages.

\begin{tabular}{lcccc}
\hline \multirow{2}{*}{ Element } & \multicolumn{5}{c}{ Weight (\%) } & & \\
& $0 \%$ & $25 \%$ & $50 \%$ & $75 \%$ \\
\hline Carbon & 1.414 & 2.881 & 7.741 & 10.499 \\
Oxygen & 41.559 & 45.223 & 46.831 & 47.24 \\
Sodium & 0.429 & 0.616 & 1.777 & 0.962 \\
Phosphorus & - & 0.16 & 1.648 & 2.345 \\
Chlorine & 0.325 & 0.565 & 1.128 & 1.547 \\
Titanium & 48.751 & 47.647 & 38.585 & 35.007 \\
Tin & 7.522 & 2.908 & 2.29 & 2.401 \\
\hline
\end{tabular}

surface. Figures $7(a)-7(d)$ and Table 1 show the element content in DSSC with the percentage of clathrin $0 \%, 25 \%, 50 \%$, and $75 \%$.

From EDS spectra as shown in Figure 7, the results of the analysis on DSSC layers obtained data on the composition of the elements contained in the DSSC layer which can be seen in Table 1. In Table 1, for 0\% clathrin in DSSC, it can be seen that there are $48.751 \%$ Ti elements and $41.559 \%$ O elements. The presence of $\mathrm{Ti}$ and $\mathrm{O}$ elements indicates the formation of $\mathrm{TiO}_{2}$ compounds, whereas the presence of element $\mathrm{C}$ is an element in chlorophyll. The presence of elements of $\mathrm{Na}, \mathrm{Cl}$, and $\mathrm{Sn}$ is an element found in FTO glass.

Figures 7(b)-7(d) and Table 1 show data from DSSC that were clathrin protein deposited. From the figure and table, there is an appearance of a new element, phosphorus. Phosphorus is one of the protein-forming elements, other than the elements carbon and oxygen [20]. With the increasing protein content added to DSSC, the elements of carbon, oxygen, and phosphorus are also increasing.

The elements of carbon, oxygen, and phosphorus in $\mathrm{TiO}_{2}$ can function as an electron transfer connector in porous $\mathrm{TiO}_{2}$ structures. Carbon compounds that form a hexagonal layer of three electrons are used to form a covalent bond with the nearest $\mathrm{C}$ atom, while the fourth electron is a free electron that moves through the surface of the layer. This free electron causes the carbon material to conduct electric current [21]. Phosphorus which has five valence electrons is a donor or an n-type doping agent. The fifth electron from the donor is not bound anywhere and can conduct electric current [22], whereas oxygen is an electron acceptor [23], which will capture the electrons produced from dye.

With the presence of carbon, oxygen, and phosphorus elements in $\mathrm{TiO}_{2}$, the charge from dye can be captured by the molecules of carbon, oxygen, and phosphorus and then can rapidly be passed on to the next $\mathrm{TiO}_{2}$ particles. This phenomenon causes the charge delivery distance to be shorter so that the electric current can be increased and improve the DSSC performance.

3.3. Function Group of DSSC. FTIR (Fourier-Transform Infrared Spectroscopy) testing was carried out to determine the functional groups formed in the DSSC layer due to the addition of clathrin protein. FTIR test results for each clathrin protein addition concentration can be seen in Figure 8 .

From the results of FTIR testing, it can be known that the functional groups formed in the DSSC layer. Figure 8 shows 

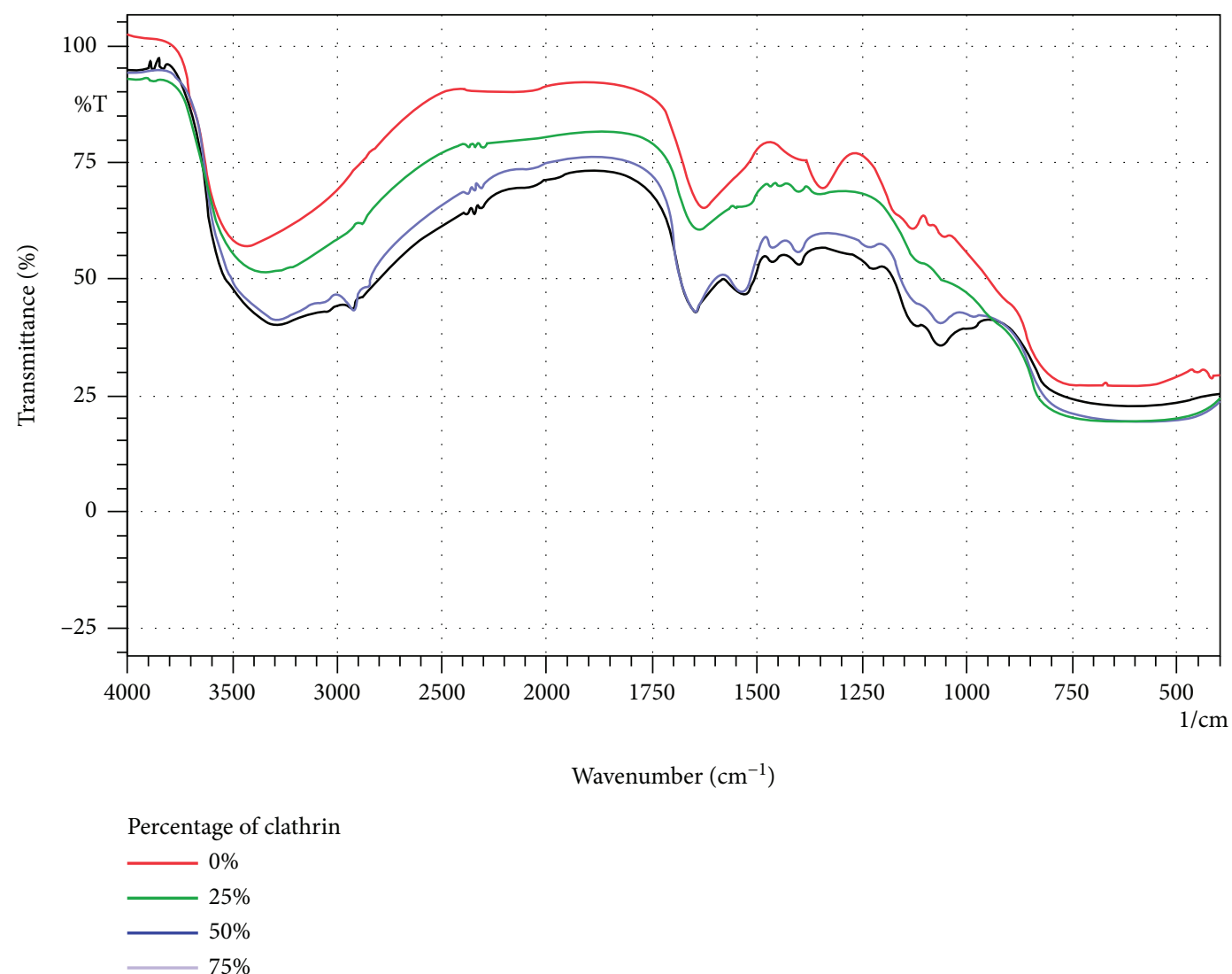

FIGURE 8: Function groups in DSSC for various percentages of clathrin.

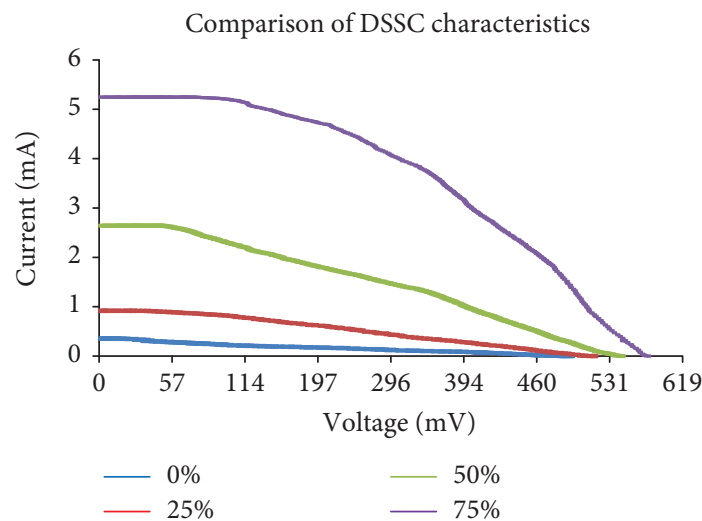

FIGURE 9: DSSC $I-V$ curve.

TABLE 2: Comparison of DSSC performance characteristics.

\begin{tabular}{lcccc}
\hline DSSC $(\%)$ & $I_{\text {sc }}(\mathrm{mA})$ & $V_{\text {oc }}(\mathrm{mV})$ & $\mathrm{FF}$ & $\eta(\%)$ \\
\hline 0 & 0.353 & 562 & 0.238 & 0.047 \\
25 & 0.917 & 590 & 0.302 & 0.164 \\
50 & 2.643 & 624 & 0.313 & 0.516 \\
75 & 5.247 & 657 & 0.425 & 1.465 \\
\hline
\end{tabular}

the appearance of peaks in the wavenumber $3300-3500 \mathrm{~cm}^{-1}$ which indicates the presence of $\mathrm{N}-\mathrm{H}$ amine/amide groups. Next appears the peak at the wavenumber $3200-3600 \mathrm{~cm}^{-1}$ which shows the presence of $\mathrm{O}-\mathrm{H}$ hydrogen bond/phenol groups. From Figure 8, it is also known that a peak appears in the wavenumber $1610-1680 \mathrm{~cm}^{-1}$ which indicates the presence of a $\mathrm{C}=\mathrm{C}$ alkena group. Furthermore, it is known that the peak appears in the wavenumber $1500-1600 \mathrm{~cm}^{-1}$ which indicates the existence of the $\mathrm{C}=\mathrm{C}$ aromatic ring group. From Figure 8, a peak also appears at wavenumbers 1500$1570 \mathrm{~cm}^{-1}$ and $1300-1370 \mathrm{~cm}^{-1}$ which indicates the presence of $\mathrm{NO}_{2}$ groups or nitro compounds. Then, it is also known from Figure 8 that a peak appears at the wavenumber $1050-1300 \mathrm{~cm}^{-1}$ which indicates the presence of a $\mathrm{C}-\mathrm{O}$ alcohol group [24].

The presence of $\mathrm{N}-\mathrm{H}$ amine, $\mathrm{C}-\mathrm{O}, \mathrm{O}-\mathrm{H}$, alkene, aromatic, and nitro compound groups shows the presence of amino acid constituent groups. Amino acids are protein constituent compounds [25].

The amino acid constituent functional groups can increase the electron transfer process in the DSSC layer because amino acids can act as acids (donating protons in strong bases) and can act as bases (accepting protons from strong acids) [26].

From Figure 8, it appears that the higher the clathrin concentration on $\mathrm{TiO}_{2}$, the sharper absorption will occur in the wavenumber of the FTIR spectrum for the constituent groups of proteins.

3.4. DSSC Performance. Current, voltage, and efficiency measurements are aimed at determining the performance of each 
DSSC as shown in Figure 9 for DSSC with clathrin percentages of $0 \%, 25 \%, 50 \%$, and $75 \%$. The performance of DSSC depends on the value of $I_{\mathrm{sc}}, V_{\mathrm{oc}}, \mathrm{FF}$, and efficiency. Changes in $I_{\mathrm{sc}}, V_{\mathrm{oc}}$, and FF values and their efficiency can be seen in Table 2.

Testing the efficiency of DSSC with the addition of $0 \%$, $25 \%, 50 \%$, and $75 \%$ clathrin protein was carried out by measuring the current-voltage $(I-V)$ curve under the halogen lamp irradiation of $1000 \mathrm{~W} / \mathrm{m}^{2}$. The characteristics of DSSC are evaluated by short circuit current $\left(I_{\mathrm{sc}}\right)$, open circuit voltage $\left(V_{\text {oc }}\right)$, Fill Factor $(\mathrm{FF})$, and energy conversion efficiency $(\eta)$ as can be seen in Table 2.

From Figure 9 and Table 2, it appears that the addition of clathrin protein will improve the performance of DSSC; this can be seen from the increase in the value of current, voltage, and efficiency of DSSC. The highest current, voltage, and efficiency values in DSSC with $75 \%$ clathrin protein addition are short circuit current $\left(I_{\mathrm{sc}}\right)$, open circuit voltage $\left(V_{\mathrm{oc}}\right)$, and efficiency $(\eta)$ of $5247 \mathrm{~mA}, 657 \mathrm{mV}$, and $1465 \%$.

The performance improvement in DSSC is caused by the addition of clathrin protein to DSSC which can function as an electron bridge between porous $\mathrm{TiO}_{2}$ molecules thereby reducing the barrier that occur in the electron transfer process and resulting in improved performance from DSSC.

\section{Conclusions}

Dye-Sensitized Solar Cell- (DSSC-) based natural dyes added with clathrin were successfully made. Addition of clathrin protein to DSSC will fill cavities between $\mathrm{TiO}_{2}$ molecules causing a reduction in the cavity between $\mathrm{TiO}_{2}$ molecules so that the transfer of electrons between $\mathrm{TiO}_{2}$ molecules becomes faster and reduces the recombination rate of electrons. The addition of clathrin protein can function as an electron bridge which reduces the barrier to the transfer of electrons between $\mathrm{TiO}_{2}$ molecules. Addition of clathrin protein to DSSC also increases the elements of carbon, oxygen, and phosphorus contained in DSSC. The presence of carbon, oxygen, and phosphorus elements in $\mathrm{TiO} 2$ causes the charge delivery distance to be shorter so that the electric current can be increased. Addition of clathrin protein to DSSC causes increasingly sharp absorption of clathrin protein constituent functional groups. The addition of $75 \%$ clathrin protein to DSSC can improve the performance of DSSC with the highest $I_{\mathrm{sc}}$, $V_{\mathrm{oc}}$, and efficiency values equal to $5247 \mathrm{~mA}, 657 \mathrm{mV}$, and $1465 \%$.

\section{Data Availability}

The data used to support the findings of this study are available from the corresponding author upon request.

\section{Conflicts of Interest}

The authors declare that they have no conflict of interest.

\section{Acknowledgments}

This research was funded by Lembaga Pengelola Dana Pendidikan- Kementerian Keuangan Republik Indonesia: Beasiswa Unggulan Dosen Indonesia-Dalam Negeri (BUDIDN) No. 20161141011775-Kementerian Riset Teknologi Dan Pendidikan Tinggi Republik Indonesia.

\section{References}

[1] B. O'Regan and M. Grätzel, "A low-cost, high-efficiency solar cell based on dye-sensitized colloidal $\mathrm{TiO}_{2}$ films," Nature, vol. 353, no. 6346, pp. 737-740, 1991.

[2] M. Gratzel, "Conversion of sunlight to electric power by nanocrystalline dye-sensitized solar cells," Journal of Photochemistry and Photobiology A: Chemistry, vol. 164, no. 1-3, pp. 314, 2004.

[3] M. K. Nazeeruddin, E. Baranoff, and M. Gratzel, "Dye-sensitized solar cells: a brief overview," Solar Energy, vol. 85, no. 6, pp. 1172-1178, 2011.

[4] Z. Arifin, S. Sudjito, W. Denny, P. Agus, and Dharmanto, "Synthesis, characterisation, and fabrication hollow fibres of Zn-doped $\mathrm{TiO}_{2}$ for dye-sensitized solar cells," Journal of Engineering Science and Technology, vol. 12, no. 5, pp. 1227-1239, 2017.

[5] J. Perlin, From Space to Earth (The Story of Solar Electricity), Harvard University Press, 1999.

[6] K. Hara, T. Horiguchib, T. Kinoshitab, K. Sayamaa, H. Sugiharaa, and H. Arakawaa, "Highly efficient photon-toelectron conversion with mercurochrome-sensitized nanoporous oxide semiconductor solar cells," Solar Energy Materials and Solar Cells, vol. 64, no. 2, pp. 115-134, 2000.

[7] H. Yu, Modification of $\mathrm{TiO}_{2}$ Photoanodes for Dye-Sensitized Solar Cells, Griffith University, 2010.

[8] H. Hu, J. Shen, X. Cao et al., "Photo-assisted deposition of Ag nanoparticles on branched $\mathrm{TiO}_{2}$ nanorod arrays for dyesensitized solar cells with enhanced efficiency," Journal of Alloys and Compounds, vol. 694, pp. 653-661, 2017.

[9] R. K. Chava and M. Kang, "Improving the photovoltaic conversion efficiency of $\mathrm{ZnO}$ based dye sensitized solar cells by indium doping," Journal of Alloys and Compounds, vol. 692, pp. 67-76, 2017.

[10] C.-S. Chou, C.-Y. Chen, S.-H. Lin, W.-H. Lu, and P. Wu, "Preparation of $\mathrm{TiO}_{2} /$ bamboo-charcoal-powder composite particles and their applications in dye-sensitized solar cells," Advanced Powder Technology, vol. 26, no. 3, pp. 711-717, 2015.

[11] D. Kuang, C. Klein, H. J. Snaith et al., "Ion coordinating sensitizer for high efficiency mesoscopic dye-sensitized solar cells: influence of lithium ions on the photovoltaic performance of liquid and solid-state cells," Nano Letters, vol. 6, no. 4, pp. 769-773, 2006.

[12] B. M. Pearse, "Clathrin: a unique protein associated with intracellular transfer of membrane by coated vesicles," Proceedings of the National Academy of Sciences of the United States of America, vol. 73, no. 4, pp. 1255-1259, 1976.

[13] M. G. Ford, B. M. Pearse, M. K. Higgins et al., "Simultaneous binding of PtdIns $(4,5) \mathrm{P}_{2}$ and clathrin by AP180 in the nucleation of clathrin lattices on membranes," Science, vol. 291, no. 5506, pp. 1051-1055, 2001. 
[14] D. Templeton, Molecular and Cellular Iron Transport, Marcel Dekker, Inc, 2002.

[15] P. N. Dannhauser, M. Platen, H. Böning, and I. A. T. Schaap, "Durable protein lattices of clathrin that can be functionalized with nanoparticles and active biomolecules," Nature Nanotechnology, vol. 10, no. 11, pp. 954-957, 2015.

[16] Schoen, "Template engineering through epitope recognition: a modular, biomimetic strategy for inorganic nanomaterial synthesis," Journal of the American Chemical Society, vol. 133, no. 45, pp. 18202-18207, 2011.

[17] A. W. Putri, F. Nurosyid, and A. Supriyanto, "Optimization of active cell area on the dye-sensitized solar cell efficiency," Journal of Physics: Conference Series, vol. 909, article 012008, 2017.

[18] S. Lee, P. Y. Chang, Y. L. Lee, and F. J. Hsu, "Characterization of dye-sensitized solar cell with $\mathrm{ZnO}$ nanorod multilayer electrode," National Kaohsiung University of Applied Sciences, pp. 1813-3851, 2007.

[19] J. D. Lloyd, The Proteins as Colloidal Electrolytes, Northeastern University, 1934.

[20] F. Fraga, A. F. Rios, F. F. Perez, and F. G. Figueiras, “Theoretical limits of oxygen:carbon and oxygen:nitrogen ratios during photosynthesis and mineralisation of organic matter in the sea," Scientia Marina, vol. 62, 1997.

[21] S. D. Littlejohn, Electrical Properties of Graphite Nanoparticles in Silicone, Springer, 2014.

[22] P. F. Pierret, Advanced Semiconductor Fundamentals, Purdue University, Second edition, 1987.

[23] P. R. Rich, "The molecular machinery of Keilin's respiratory chain," Biochemical Society Transactions, vol. 31, no. 6, pp. 1095-1105, 2003.

[24] D. A. Skoog, F. J. Holler, and S. R. Crouch, Principles of Instrumental Analysis, Thomson Brooks/Cole, Sixth edition, 2007.

[25] R. W. Thatcher, The Chemistry of Plant Life, McGraw-Hill Book Company, First edition, 1921.

[26] S. P. Lin, Amino Acids and Proteins, Institute of Biomedical Engineering, National Chung Hsing University, 2010. 

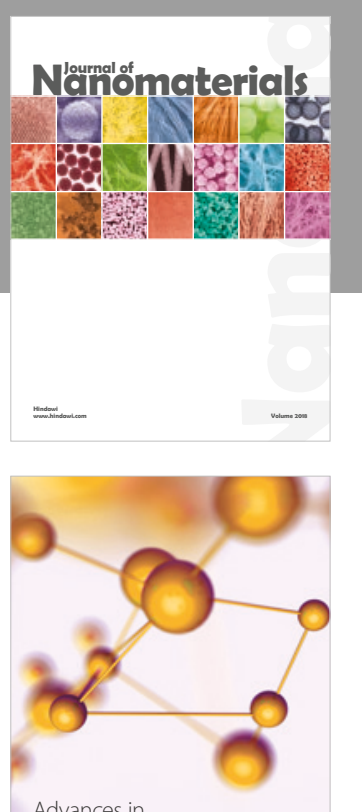

Physical Chemistry
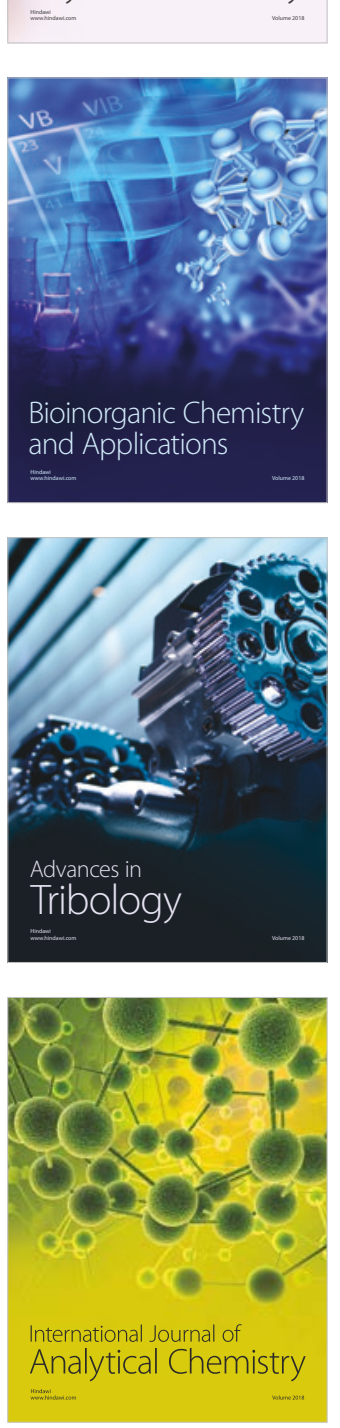

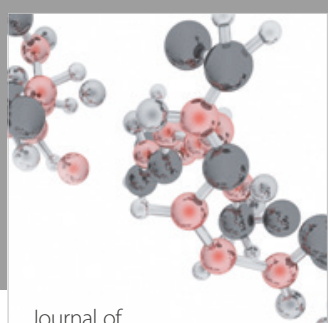

Analytical Methods

in Chemistry

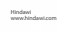

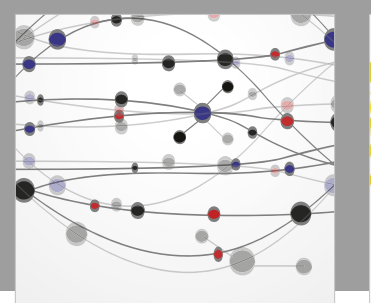

The Scientific World Journal

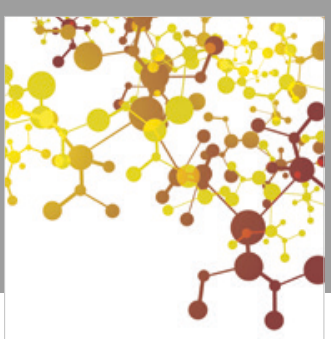

Journal of

Applied Chemistry
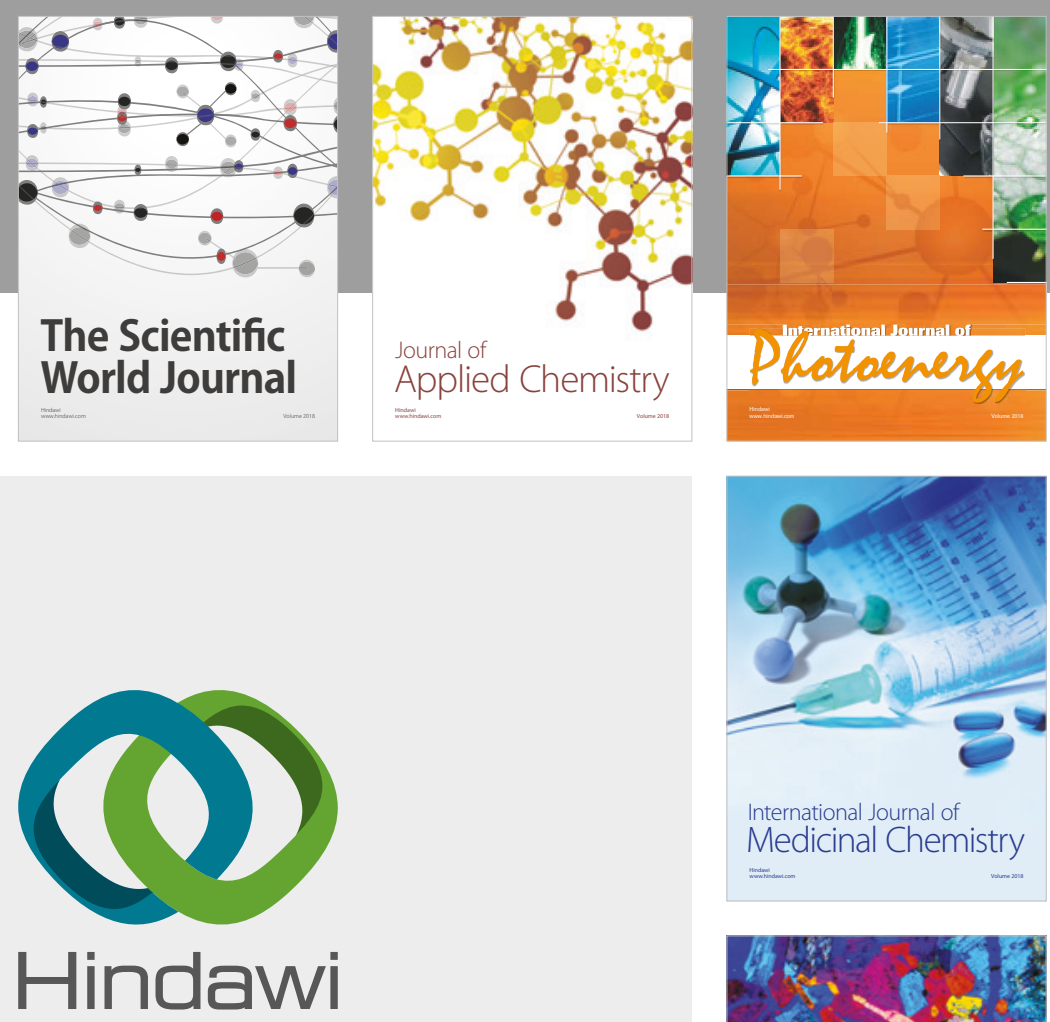

Submit your manuscripts at

www.hindawi.com
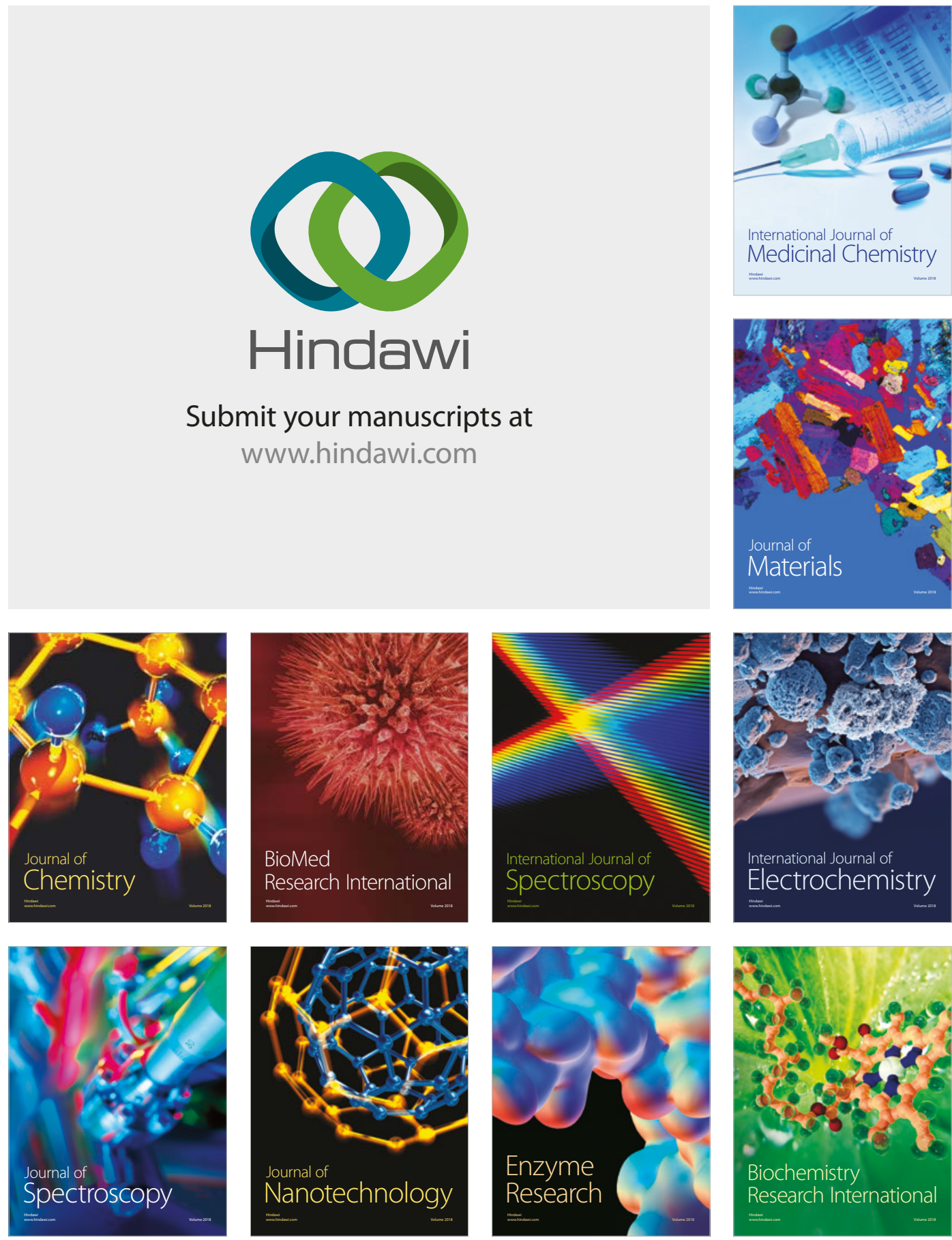
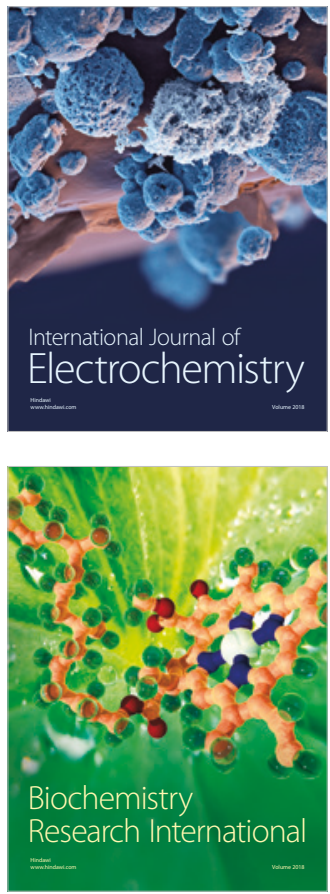